\title{
2 The response of perennial and temporary headwater stream 3 invertebrate communities to hydrological extremes
}

\author{
4 Rachel Stubbington - Adam M. Greenwood • \\ 5 Paul J. Wood · Patrick D. Armitage · John Gunn • \\ 6 Anne L. Robertson
}

7 Received: 20 August 2008/Revised: 24 April 2009/Accepted: 8 May 2009

8 (C) Springer Science+Business Media B.V. 2009

9 Abstract The headwaters of karst rivers experience 10 considerable hydrological variability, including 11 spates and streambed drying. Extreme summer 12 flooding on the River Lathkill (Derbyshire, UK) 13 provided the opportunity to examine the invertebrate 14 community response to unseasonal spate flows, flow 15 recession and, at temporary sites, streambed drying. 16 Invertebrates were sampled at sites with differing 17 flow permanence regimes during and after the spates. 18 Following streambed drying at temporary sites,
Electronic supplementary material The online version of this article (doi:10.1007/s10750-009-9823-8) contains supplementary material, which is available to authorized users.

Handling editor: Sonja Stendera

R. Stubbington $(\triangle)$ · A. M. Greenwood · P. J. Wood Department of Geography, Loughborough University, Loughborough, Leicestershire LE11 3TU, UK e-mail: R.Stubbington@lboro.ac.uk

\section{P. D. Armitage}

Centre for Ecology and Hydrology, Freshwater Biological Association, East Stoke, Dorset BH20 6BB, UK

\section{J. Gunn}

Limestone Research Group, School of Geography, Earth and Environmental Sciences, University of Birmingham, Edgbaston, Birmingham B15 2TT, UK

Centre for Research in Ecology and the Environment, School of Human and Life Sciences, Roehampton University, Holybourne Avenue, London SW15 4JD, UK

\section{A. L. Robertson}

dewatered surface sediments were investigated as a refugium for aquatic invertebrates. Experimental rehydration of these dewatered sediments was conducted to promote development of desiccation-tolerant life stages. At perennial sites, spate flows reduced invertebrate abundance and diversity, whilst at temporary sites, flow reactivation facilitated rapid colonisation of the surface channel by a limited number of invertebrate taxa. Following streambed drying, 38 taxa were recorded from the dewatered and rehydrated sediments, with Oligochaeta being the most abundant taxon and Chironomidae (Diptera) the most diverse. Experimental rehydration of dewatered sediments revealed the presence of additional taxa, including Stenophylax sp. (Trichoptera: Limnephilidae) and Nemoura sp. (Plecoptera: Nemouridae). The influence of flow permanence on invertebrate community composition was apparent despite the aseasonal high-magnitude flood events. Flow permanence was also critical in determining the community response to the spate flows. Following streambed drying at temporary sites, the surficial sediments overlying the karstic bedrock functioned as an effective refugium for many taxa. The development of aquatic insects following experimental rehydration indicated that these taxa survived in dewatered sediments as desiccation-resistant eggs.

Keywords Flow permanence Spate . Streambed drying - Disturbance - Refugia . Sediment rehydration

\begin{tabular}{|l|lll|}
\hline \multirow{2}{*}{ Journal : Medium 10750 } & Dispatch : & 16-5-2009 & Pages: 14 \\
& Article No. : $\mathbf{9 8 2 3}$ & $\square$ LE & $\square$ TYPESET \\
MS Code : HYDR3726 & $\checkmark$ CP & $\checkmark$ DISK \\
\hline
\end{tabular}




\section{Introduction}

Hydrological variability is a critical factor in structuring lotic freshwater habitats and in determining the composition of instream communities (Lytle \& Poff, 2004; Monk et al., 2008). Flow permanence, in particular, has been demonstrated to have a greater influence on instream macroinvertebrate assemblages than many other physiochemical variables, resulting in significant differences in community composition between perennial and adjacent temporary sites (Erman \& Erman, 1995; Smith \& Wood, 2002). Temporary streams naturally experience a wide range of hydrological conditions, including floods and streambed desiccation, and these conditions can occur in quick succession (Lytle, 2000). Such hydrological extremes may act as the principal influence structuring instream communities including benthic and hyporheic invertebrates (Meyer et al., 2003; Smith et al., 2003; Datry et al., 2007).

Flooding may cause dramatic reductions in both invertebrate species richness and community abundance, due to the scouring and erosive action of high flows (Olsen \& Townsend, 2005). At the other extreme of the hydrological continuum, regular drying of the streambed may strongly influence the structure of lotic invertebrate communities and lead to the exclusion of taxa reliant on flowing and/or free water habitats (Boulton, 2003). In particular, a temporary flow regime may exclude bivoltine and multivoltine taxa, species with lifecycles exceeding one year, and those with a significant aquatic growth phase coincident with the summer drought period, as these groups may be unable to complete the aquatic phase of their lifecycle between drying events (Wright, 1981; Smith \& Wood, 2002).

To date, most research on the ecology and survival strategies of invertebrates in temporary waters has been conducted in Mediterranean and semi-arid systems (e.g. Stanley et al., 1994), despite the relatively common occurrence of temporary lotic ecosystems in temperate environments, particularly in karst landscapes (Meyer et al., 2003; Datry et al., 2007). Fauna inhabiting such temporary waters require adaptations that promote resistance (the ability to tolerate a disturbance) and/or resilience (the ability to recover following a disturbance) (sensu Lake, 2000) to streambed drying. These adaptations include physiological, behavioural, morphological and life history strategies (Humphries \& Baldwin, 2003). Physiological adaptations to habitat drying include desiccation tolerant egg, larval or adult stages in either a dormant or active state (Williams, 2006). Life-history adaptations, common in aquatic insects, involve the synchronisation of terrestrial life stages with regular streambed drying events (e.g. Salavert et al., 2008), although such strategies may not promote persistence during unpredictable hydrological disturbances (Lytle \& Poff, 2004).

Behavioural adaptations centre on the use of physical habitat refugia that minimise exposure to adverse hydrological conditions (Lancaster \& Hildrew, 1993). Refugia during drying events are areas that retain either free water or maintain relatively high humidity (Boulton, 1989). The hyporheic zone has been demonstrated to act as a refugium during both spates and streambed drying (e.g. Dole-Olivier \& Marmonier, 1992; Clinton et al., 1996). However, a well-developed, saturated hyporheic zone, as is commonly associated with alluvial sediments, is not present in all the riverine systems. In karst rivers, for example, the substratum in the headwaters may be principally composed of shattered limestone bedrock (i.e. the epikarst: Pipan, 2005) overlain in places by finer sediments.

This article examines the response of aquatic invertebrates in both perennial and temporary reaches of the River Lathkill (Derbyshire, UK) to an unusual sequence of hydrological extremes, including a severe summer flood, declining flow, and at some temporary sites, streambed drying. Following drying at temporary sites, the refugial capacity of the dewatered sediments overlying the epikarstic bedrock was investigated. We hypothesise that (i) distinct invertebrate communities will occur at sites with differing flow permanence, and that differences in community composition will be evident despite varying hydrological conditions; and that (ii) drying of the streambed at temporary sites will eliminate some taxa, whilst others will have adaptations facilitating their survival in the dewatered sediments.

\section{Methods}

Study area

The River Lathkill, located within the White Peak area of the Peak District (Derbyshire, England; $53^{\circ} 11.2^{\prime} \mathrm{N}$,
140 142

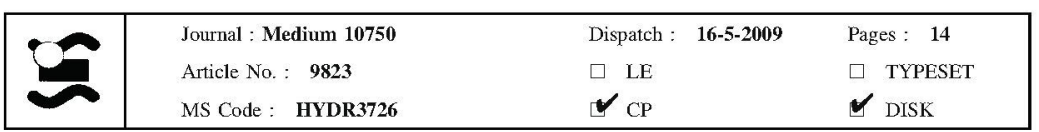


$\left.1^{\circ} 44.4^{\prime} \mathrm{W}\right)$, is underlain by carboniferous limestone, which manifests as a karst landscape. The River Lathkill rises from the centre of the limestone outcrop and primarily discharges autogenic water (i.e. water that has only been in contact with carbonate rocks). The climate of this region is temperate, with a mean annual rainfall of $\sim 1,200 \mathrm{~mm}$, and a mean annual air temperature of $8.0^{\circ} \mathrm{C}$, ranging from a mean of $1.7^{\circ} \mathrm{C}$ in January to $14.5^{\circ} \mathrm{C}$ in July (Wood et al., 2005).

Classification of the flow regimes experienced by temporary lotic freshwaters has rarely been attempted from an ecological perspective, reflecting the difficulty in defining boundaries between diverse habitat types (Hughes, 2005). A scheme proposed by Williams (2006) classified habitats into five groups (ephemeral, episodic, intermittent, seasonal and near-permanent) based on the length of the dry phase. However, the broad range of flow regimes encompassed by each of these groups renders this system inappropriate for investigations conducted at small spatial scales where a natural gradient of flow permanence exists. In the current investigation, Williams' (2006) classification scheme was therefore modified to reflect the variability in flow permanence regimes: the term 'ephemeral' is applied to sites typically dry for $>6$ months each year and experiencing rapid flow resumptions following sustained high rainfall inputs, whereas 'intermittent' is used to describe sites that also dry annually but for $<6$ months. The term 'transitional' is used to refer to sites that become dry for only a slightly shorter period than intermittent sites in some years but, crucially, had not dried prior to the start of this study. The term 'temporary' is used in this study as a general term to refer to all sites that are not perennial.

With this classification scheme in use, the Lathkill is ephemeral from its source downstream for a distance of $\sim 250 \mathrm{~m}$, this reach typically remaining dry throughout the summer months (Head cave, no.1, Fig. 1). The tributary Cales Dale, which has a common catchment with the Lathkill, experiences similar flow conditions to the ephemeral main channel sites. In addition, the valley upstream of the source (Fig. 1, A) is ephemeral, with water being present here only sporadically during periods of high flow. The Lathkill becomes intermittent downstream of the ephemeral reach, with the duration of the dry phase gradually decreasing with progression downstream. A series of spring inputs (Holme Grove Risings, Fig. 1) results in the increased flow permanence that characterises the transitional reach, which did not dry in 2007 prior to the beginning of this study. Downstream of further spring inputs and Cales Dale, the river is perennial for the remainder of the study area. The substrate of the Lathkill headwaters comprises exposed epikarstic bedrock interspersed with areas of finer sediments, which are overlain in places by limestone boulders, cobbles and gravelsized clasts and are stabilised by semi-aquatic and terrestrial vegetation.

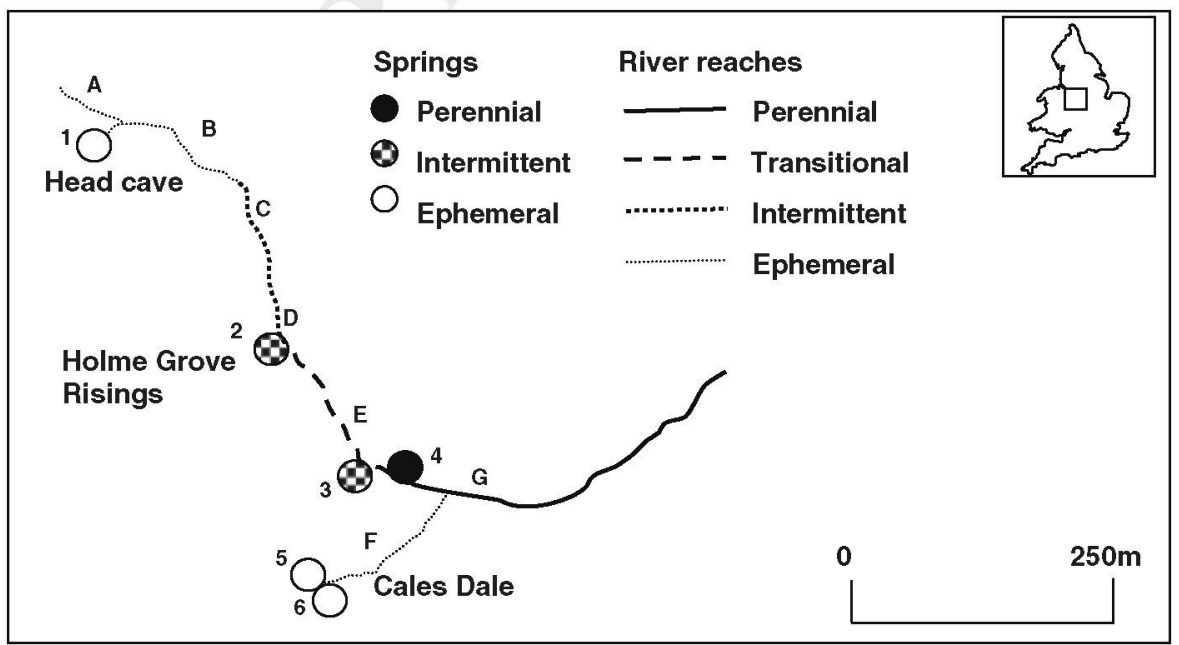

Fig. 1 Map of the headwaters of the River Lathkill showing the sampling locations in the main river channel and in springs with differing flow permanence. $A-G=$ main river sampling sites, $1-6=$ spring sampling sites

\begin{tabular}{|l|lll|}
\hline & Journal : Medium 10750 & Dispatch : 16-5-2009 & Pages : 14 \\
Article No. : 9823 & $\square \mathrm{LE}$ & $\square$ TYPESET \\
MS Code : HYDR3726 & $\checkmark \mathrm{CP}$ & $\checkmark$ DISK \\
\hline
\end{tabular}


Under normal conditions, the headwaters of the River Lathkill remain dry between April and May and then remain largely dry throughout the summer until flow resumes in October. There may, however, be unpredictable flow resumptions, particularly towards the start and end of the dry phase, in response to heavy and prolonged rainfall. In spring 2007, the drying sequence followed the normal pattern, with the whole surface water being lost from the ephemeral and intermittent reaches by the end of April. However, in a series of events between 13th and 23rd June, precipitation reached over $100 \mathrm{~mm}$ and although there was little streamflow response in the Lathkill, these inputs recharged the soil and groundwater stores. Consequently, when an extreme event deposited $55 \mathrm{~mm}$ of precipitation in $<24 \mathrm{~h}$ during $24-25$ June, flow resumed throughout the headwaters, with discharge at a downstream gauging site showing a dramatic increase from $250 \mathrm{l} / \mathrm{s}$ to $3,600 \mathrm{l} / \mathrm{s}$. Although several larger spates have been recorded between 1997 and 2007, this was the largest flood event in the Lathkill catchment between April and September during this ten-year period. Further heavy rainfall events resulted in two smaller spates, with flows peaking on 5th and 16th July. These flood events included flow in the valley upstream of the source of the river (Fig. 1, A), and occurred during a period of widespread, extreme flood events in England and Wales (Marsh, 2008). Subsequently to these floods, discharge declined, with the head of the river gradually migrating downstream over the next 4 weeks. Surface water was again lost from the ephemeral and intermittent reaches 47 days after flow had resumed (9th August), and the channel then remained dry until after the end of the study (3rd October). Flow at the downstream gauging site declined to $320 \mathrm{l} / \mathrm{s}$ by the 9 th August and continued to decline throughout the study period.

\section{Sampling}

Aquatic invertebrates were sampled on seven dates between 29th June and 3rd October 2007. A total of 13 sites were sampled during the study period. Of these, six sites are located on the main channel of the River Lathkill (Fig. 1, A-E and G) whilst one site is located on the tributary, Cales Dale (Fig. 1, F). These main channel sites comprised three ephemeral, two intermittent, one transitional and one perennial site. In addition, six springs adjacent to the river and tributary were sampled (Fig. 1, 1-6), amongst which three were ephemeral, two intermittent and one perennial. These sites represent the range of hydrological conditions occurring along the gradient of flow permanence found in the Lathkill headwaters. The number of samples taken to characterise the macroinvertebrate community at sites in each of the four flow permanence categories on each sampling date was not equal due to prohibitively high flows at transitional and perennial sites during the spates and the drying of ephemeral and intermittent sites as the study proceeded (Table 1).

The aquatic invertebrate community was sampled using two complementary techniques. In order to characterise community diversity at each main channel site, the semi-quantitative kick sampling technique was conducted using a pond (hand) net $(900 \mu \mathrm{m}$ mesh, $230 \times 255 \mathrm{~mm}$ frame, $275 \mathrm{~mm}$ bag depth) attached to a $1.5 \mathrm{~m}$ handle according to Furse et al. (1981). In addition, in order to fully quantify the community, Surber samples $\left(0.1 \mathrm{~m}^{2}\right.$ frame with a $250 \mu \mathrm{m}$ mesh net) were collected by manually disturbing the substrate within the frame area to a depth of $\sim 5 \mathrm{~cm}$ over a 30 -s period. Large clasts located within the Surber frame were inspected individually and attached invertebrates removed and added to the sample. All the samples were preserved in the field with $10 \%$ formaldehyde solution prior to processing and identification in the laboratory. At each sampling location, water temperature $\left({ }^{\circ} \mathrm{C}\right), \mathrm{pH}$, dissolved oxygen $\left(\mathrm{mg}^{-1}\right)$ and conductivity ( $\mu \mathrm{S} \mathrm{cm}^{-1}$ ) were measured in situ using standard instrumentation (Hanna Instruments).

Subsequent to streambed drying in the ephemeral and intermittent reaches, dewatered sediment samples were collected from the three main channel sites (Fig. 1, B, D and F) and three springs (Fig. 1, 1,5 and 6), on three dates (9th and 20th August, and 7th September), and from one site (Fig. 1, D) on a fourth date (3rd October). At each site, two samples, each weighing approximately $1 \mathrm{~kg}$, were extracted from the channel using a trowel. Clasts greater than $10 \mathrm{~mm}$ in size and terrestrial vegetation were excluded from the samples, whilst desiccated aquatic vegetation (primarily bryophytes) was retained. All the sediment samples were returned to the laboratory and weighed. One sample from each pair was preserved in a $10 \%$ formaldehyde solution for later processing and identification of

\begin{tabular}{|l|lll|}
\hline & Journal : Medium 10750 & Dispatch : 16-5-2009 & Pages : 14 \\
Article No. : 9823 & $\square$ LE & $\square$ TYPESET \\
MS Code : HYDR3726 & $\checkmark$ CP & $\checkmark$ DISK \\
\hline
\end{tabular}


Table 1 Total taxon richness, mean abundance $(+/-1 \mathrm{SE})$ and total abundance of invertebrate taxa with $>85 \%$ occurrence at perennial, transitional, intermittent and/or ephemeral sites in the headwaters of the River Lathkill

\begin{tabular}{|c|c|c|c|c|}
\hline & $\begin{array}{l}\text { Ephemeral } \\
\left(\mathrm{A}, \mathrm{B}, \mathrm{F}, 1,5,6^{\mathrm{a}}\right)\end{array}$ & $\begin{array}{l}\text { Intermittent } \\
\left(\mathrm{C}, \mathrm{D}, 2,3^{\mathrm{a}}\right)\end{array}$ & Transitional $\left(\mathrm{E}^{\mathrm{a}}\right)$ & Perennial $\left(\mathrm{G}, 4^{\mathrm{a}}\right)$ \\
\hline Number of Surber samples & 15 & 9 & 14 & 8 \\
\hline Number of kick samples & 12 & 10 & 5 & 2 \\
\hline Total number of taxa & 9 & 15 & 29 & 32 \\
\hline Total number of families & 9 & 15 & 25 & 29 \\
\hline Mean abundance (individuals $0.1 \mathrm{~m}^{-2}$ ) & $8.8(+/-2.2)$ & $25(+/-6.2)$ & $548(+/-211.9)$ & $431(+/-132.4)$ \\
\hline \multicolumn{5}{|l|}{ Total abundance $\mathrm{b}^{\mathrm{b}}$} \\
\hline \multicolumn{5}{|l|}{ Turbellaria } \\
\hline Dugesia lugubris group & & & 161 & 113 \\
\hline Polycelis spp. & & & 2 & \\
\hline \multicolumn{5}{|l|}{ Gastropoda } \\
\hline Ancylus fuviatilis & & & & 98 \\
\hline Lymnaea peregra & & & 8 & 10 \\
\hline Lymnaea truncatula & & 6 & & \\
\hline Zonitoides spp. & 8 & 6 & & \\
\hline \multicolumn{5}{|l|}{ Crustacea } \\
\hline Gammarus pulex & & & 8696 & 3073 \\
\hline Ostracoda & & & 20 & \\
\hline \multicolumn{5}{|l|}{ Ephemeroptera } \\
\hline Baetis spp. & & & & 51 \\
\hline Habrophlebia fusca & & & & 2 \\
\hline Serratella ignita & & & & 16 \\
\hline \multicolumn{5}{|l|}{ Plecoptera } \\
\hline Diura bicaudata & & & & 12 \\
\hline Isoperla grammatica & & & & 37 \\
\hline Leuctra spp. & & & & 10 \\
\hline \multicolumn{5}{|l|}{ Trichoptera } \\
\hline Drusus annulatus & & & 3 & 7 \\
\hline Plectrocnemia conspersa & & & & 3 \\
\hline \multicolumn{5}{|l|}{ Coleoptera } \\
\hline Elmis aenea (larvae) & & & & 2 \\
\hline \multicolumn{5}{|l|}{ Helophorus sp. (larvae) } \\
\hline Helophorus brevipalpis (adult) & & 34 & 37 & \\
\hline Hydraena spp. (adult) & & & & 2 \\
\hline \multicolumn{5}{|l|}{ Diptera } \\
\hline Ceratopogonidae & & & 21 & \\
\hline Chironomidae & & & 6533 & 4279 \\
\hline Simuliidae & & & 4 & 17 \\
\hline Stratiomyidae & & & & 9 \\
\hline Hydracarina & & & 3 & \\
\hline
\end{tabular}

${ }^{a}$ Letters and numbers refer to site locations detailed in Fig. 1

$\mathrm{b}$ The total number of individuals recorded from all the samples

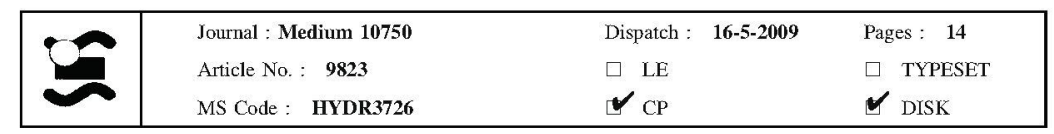


invertebrates (subsequently referred to as dewatered), and the other rehydrated with dechlorinated water at ambient air temperature (subsequently referred to as rehydrated).

Rehydration experiments were conducted within aerated 101 containers. Each container was sealed with a perforated lid, the holes being plugged with cotton wool to prevent the colonisation by external invertebrates and the escape of emerging aquatic insects. The containers were checked daily for the presence of active aquatic invertebrates, including recently emerged adult insects. All the observed invertebrates (including meiofauna) were removed and preserved in $10 \%$ formaldehyde solution for later identification. Rehydration experiments were terminated after 28 days and the sediment preserved for subsequent processing and identification of the remaining invertebrates.

Sediment samples were processed under a dissecting microscope (60.5 magnification) to facilitate observation of meiofauna. Invertebrates from all the samples (Surber, kick and sediment) were identified to the lowest taxonomic resolution possible, usually species level, except for the Diptera (Ceratopogonidae, Dixidae, Empididae, Psychodidae, Tipulidae and some Chironomidae), Harpacticoida, Ostracoda, Nematoda, some Cyclopoida, and some Oligochaeta. Sub-samples of Chironomidae and Cyclopoida from sediment samples were selected for species level identification.

\section{Statistical analysis}

Quantitative invertebrate community data collected during the period of surface flow (i.e. all Surber samples) were analysed with detrended correspondence analysis (DCA) using the program CANOCO 4.5 (ter Braak \& Šmilauer, 2002). Prior to analysis, data were log-transformed $(\ln +1)$ to reduce the effect of very abundant taxa at the centre of the ordination, and rare taxa were downweighted. Subsequent to this analysis, DCA axis scores were correlated with sample dates to examine their potential influence on community structure. The Shannon-Wiener and Simpson's diversity indices and the Berger-Parker dominance index were calculated using the program Species Diversity and Richness 3.03 (Pisces Conservation Ltd., 2002). These indices, along with the number of taxa and total invertebrate abundance (individuals
$0.1 \mathrm{~m}^{-2}$ ), were used as dependent variables in subsequent analyses. One-way analysis of variance (ANOVA) with Tukey-Kramer honestly significant difference (HSD) tests (Tukey, 1949; Kramer, 1956) were used to examine differences in the invertebrate community: (i) spatially, along the gradient of flow permanence; (ii) temporally, from spate through to baseflow; and (iii) between spring and main channel sampling sites. Paired $t$-tests were used to examine spatial and temporal differences in the measured water parameters. Preliminary analysis indicated that spring and main channel sites supported similar communities and had similar values for all the measured water parameters, and samples taken from both types of site were therefore considered together in subsequent analyses. Statistical analyses were undertaken using the program SPSS 14.0 (SPSS Inc., Chicago).

\section{Results}

Water temperature, $\mathrm{pH}$, dissolved oxygen and conductivity measurements taken whilst surface flow persisted were similar for all the sites, with no significant differences in any parameter between perennial, transitional, intermittent and ephemeral sites on individual sampling dates. Water temperature varied between $8.6-11.2^{\circ} \mathrm{C}$ during the study period, but did not change significantly between sampling dates ( $t$-test, $P=0.106$ ). The $\mathrm{pH}$ was neutral to slightly alkaline (7.0-8.1), and did not vary significantly between sampling dates ( $t$-test, $P=0.480$ ). Dissolved oxygen varied between $12.6 \mathrm{mg}^{-1}$ and $3.86 \mathrm{mg} 1^{-1}$ with a significant reduction in concentrations from June (mean $10.2 \mathrm{mg} \mathrm{l}^{-1}$ ) to October (mean $5.4 \mathrm{mg} \mathrm{l}^{-1}$ ) ( $t$-test, $P=0.006$ ). Conductivity varied considerably, between $277 \mu \mathrm{S} \mathrm{cm} \mathrm{cm}^{-1}$ and $662 \mu \mathrm{S} \mathrm{cm}^{-1}$, declining slightly throughout the study period until the last date, when values were at their highest ( $t$-test, $P=0.049$ ).

Spatial variability in community composition

One-way ANOVA of invertebrate community data 384 indicated that species richness (number of taxa) $(P=385$ $0.001 ; F$-ratio $=7.07)$, total abundance $(P=0.025 ; \quad 386$ $F$-ratio $=3.45)$, the Berger-Parker dominance index 387 $(P=0.018 ; \quad F$-ratio $=3.74)$ and the Simpson's 388

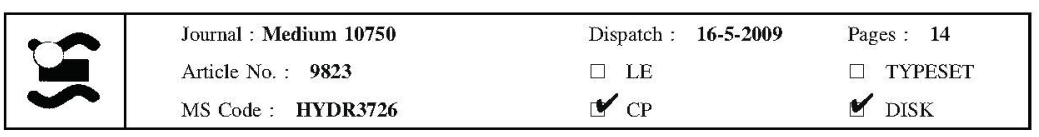


Diversity index $(P<0.001 ; F$-ratio $=8.21)$ were all significantly different at sites with differing flow permanence regimes, whilst Shannon-Wiener's did not differ significantly $(P=0.286 ; F$-ratio $=1.302$ ). Species richness was significantly higher at perennial sites $\left(\right.$ mean $=8.1$ taxa $0.1 \mathrm{~m}^{-2}$; total taxa $=32$ ) than at intermittent sites (mean $=3.4$ taxa $0.1 \mathrm{~m}^{-2}$; total taxa $=15$; Tukey-Kramer test, $P=0.029$ ) and ephemeral sites (mean $=2.9$ taxa $0.1 \mathrm{~m}^{-2}$; total taxa $=9$; Tukey-Kramer test, $P<0.001$ ), but was not significantly different to transitional sites (mean $=5.2$ taxa $0.1 \mathrm{~m}^{-2}$; total taxa $=29$; TukeyKramer test, $P>0.05$ ). Invertebrate abundance was the highest at transitional sites (mean $=548.4$ ind. $0.1 \mathrm{~m}^{-2}$ ), and was also high at perennial sites (mean $=431.2$ ind. $0.1 \mathrm{~m}^{-2}$ ), although abundance at both site types was highly variable (Table 1). Abundance was considerably lower at intermittent sites compared to transitional and perennial sites (mean $=25$ ind. $0.1 \mathrm{~m}^{-2}$ ) and was much lower at ephemeral sites than at all the sites with greater flow permanence (mean $=8.7$ ind. $0.1 \mathrm{~m}^{-2}$ ), although these differences were not significant. Berger-Parker dominance was the highest at perennial (mean = 0.76 ) and transitional sites (mean $=0.75$ ), and was lower at intermittent sites (mean $=0.62$ ), although this was not significant. Berger-Parker dominance was the lowest at ephemeral sites (mean $=0.58$ ), this being significantly different to both perennial and transitional sites (Tukey-Kramer test, $P<0.05$ ) but not intermittent sites. Simpson's diversity was the highest at ephemeral sites (mean $=2.96$ ), and was significantly higher here than at transitional sites (mean 1.64; Tukey-Kramer test, $P<0.001$ ) and perennial sites $($ mean $=1.78$; Tukey-Kramer test, $P=0.002$ ), but not intermittent sites (mean $=2.22$; Tukey-Kramer test, $P>0.05$ ).

Axes 1 and 2 of the detrended correspondence analysis (DCA) accounted for $18.4 \%$ and $12.8 \%$ of the variance in the species data, respectively. The DCA ordination plot indicated that samples were separated on axis 1 according to flow permanence (Fig. 2). Samples from perennial sites plotted as a broad group with relatively high values on axis 1 and overlapped with samples from transitional sites. The transitional samples in turn overlapped with samples from both intermittent and, to a lesser extent, ephemeral sites. Samples from intermittent and ephemeral sites formed a cluster with relatively low

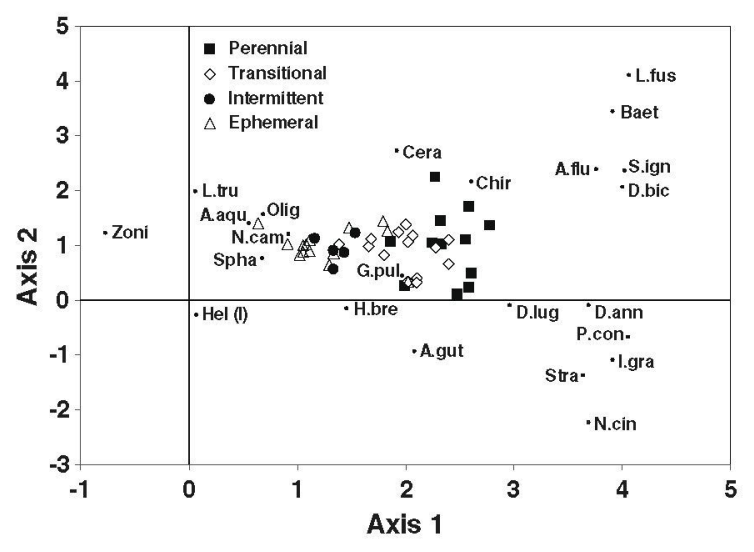

Fig. 2 Detrended correspondence analysis (DCA) of samples (classified based on flow permanence; different symbols indicate different flow regimes) and selected macroinvertebrate taxa (dots) collected from the River Lathkill. Taxon abbreviations: A.gut, Agabus guttatus; A.flu, Ancylus fluviatilis; A.aqu, Asellus aquaticus; Baet, Baetis spp.; Cera, Ceratopogonidae; Chir, Chironomidae; D.ann, Drusus annulatus; D.bic, Diura bicaudata; D.lug, Dugesia lugubris-polychroa group; G.pul, Gammarus pulex; H.bre, Helophorus brevipalpis (adult); Hel (1), Helophorus spp. (larvae); I.gra, Isoperla grammatica; L.fus, Leuctra fusca; L.tru, Lymnaea truncatula; N.cam, Nemoura cambrica; N.cin, Nemoura cinerea; Olig, Oligochaeta; P.con, Plectrocnemia conspersa; S.ign, Serratella ignita; Spha, Sphaeriidae; Zoni, Zonitidae

axis 1 values. The few taxa recorded predominantly at ephemeral and intermittent sites had low axis 1 scores, including the gastropods Zonitoides spp. and Lymnaea truncatula, and Helophorus spp. larvae (Coleoptera: Helophoridae), which was the only taxon recorded exclusively at ephemeral sites (Table 1). All the taxa associated with intermittent and ephemeral habitats occurred at very low abundances $\left(<5\right.$ individuals $0.1 \mathrm{~m}^{-2}$ ); most of the community at these sites therefore comprised ubiquitous taxa. These included Gammarus pulex (Amphipoda: Gammaridae), which accounted for $38.3 \%$ of the community at perennial sites, $50.9 \%$ at transitional sites, $50.4 \%$ at intermittent sites and $36.9 \%$ at ephemeral sites; $G$. pulex, therefore, plotted towards the centre of the DCA ordination. Other taxa dominating the intermittent and ephemeral communities occurred at similar abundances throughout the study area, for example the mean abundance of the Oligochaeta was between 2.2 and 4.8 individuals $0.1 \mathrm{~m}^{-2}$ at sites with all flow permanence regimes; however, this accounted for only $0.5 \%$ of the

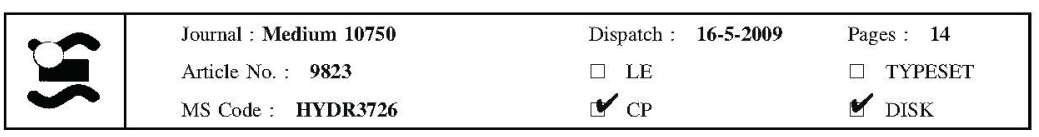


community at perennial sites, increasing to $29.9 \%$ at ephemeral sites; the Oligochaeta therefore plotted on the left of the DCA ordination. Similarly, P. personatum and Asellus aquaticus (Isopoda: Asellidae) were ubiquitous, but only comprised a significant proportion of the community at intermittent and ephemeral sites, where they accounted for $15.2 \%$ and $8.2 \%$ of all the individuals, respectively. Many taxa were recorded exclusively at sites with greater flow permanence, and therefore had high axis 1 scores. These taxa included all Ephemeroptera (Baetis sp. and Serratella ignita), Plecoptera (Diura bicaudata, Isoperla grammatica, Leuctra fusca and L. hippopus) and Trichoptera (Drusus annulatus and Plectrocnemia conspersa), and the Diptera families, Ceratopogonidae and Stratiomyidae (Table 1). The most common taxon at perennial sites was the Chironomidae (Diptera), accounting for $54.7 \%$ of the community, and similarly at transitional sites, chironomids comprised $45.7 \%$ of all the individuals.

Samples were separated on axis 2 of the DCA ordination based on hydrological conditions, with samples taken during high flows having high values on axis 2, and those taken as flow declined being distributed sequentially along the axis (Fig. 2). However, the correlation between sampling dates (i.e. hydrological conditions) and the axis 2 sample scores was only strong for transitional ( $r=0.94$ ) and perennial $(r=0.90)$ sites, whilst no significant correlation was recorded for either intermittent or ephemeral sites ( $r=0.01$ and $r=0.02$, respectively).

Temporal variability in community composition from flood to flow cessation

Five days after the reactivation of flow at the ephemeral and intermittent sites, four taxa were recorded: G. pulex, A. aquaticus, Pisidium personatum and Oligochaeta, the latter being the most numerous group with abundance peaking at 11 individuals $0.1 \mathrm{~m}^{-2}$ at an intermittent site (Fig. 1,site D). Total invertebrate abundance remained relatively low at the ephemeral and intermittent sites throughout the study period, reaching a maximum of 39 individuals $0.1 \mathrm{~m}^{-2} 19$ days after flow resumed (Fig. 3a). Small increases in the number of taxa and the ShannonWiener diversity index were observed at ephemeral and intermittent sites shortly after the resumption
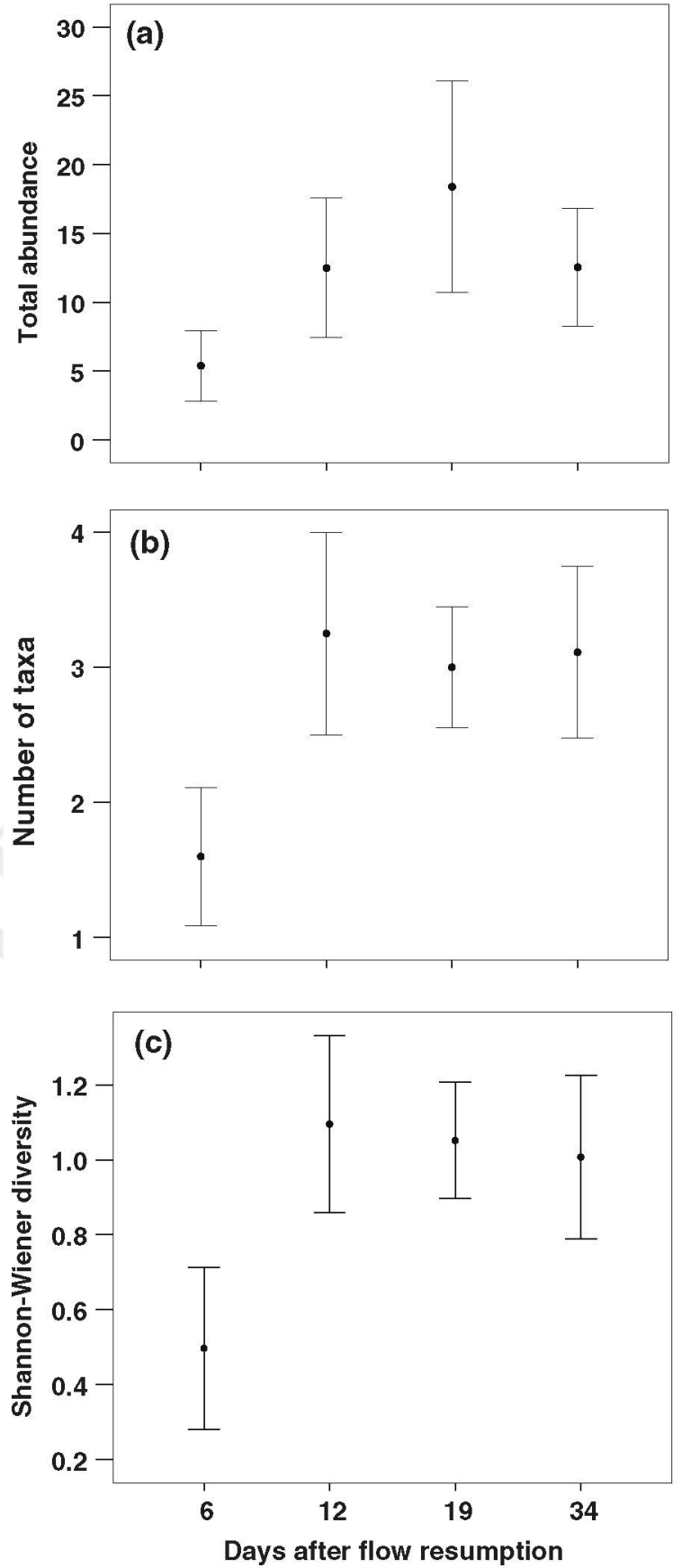

Fig. 3 Community composition (mean $\pm 1 \mathrm{SE}$ ) recorded at ephemeral and intermittent sites subsequent to flow reactivation on the River Lathkill. Shown are a total abundance, $\mathbf{b}$ number of taxa, and $\mathbf{c}$ Shannon-Wiener diversity. Number of samples: day $6: n=6$; day 12: $n=2$; day 19: $n=5$; day $34: n=10$

of flow; however, these as well as changes in Simpson's diversity were not significant $(P>0.05$; Fig. $3 b$ and c).

\begin{tabular}{|l|lll|}
\hline \multirow{2}{*}{} & Journal : Medium 10750 & Dispatch : $16-5-2009$ & Pages : 14 \\
& Article No. : 9823 & $\square$ LE & $\square$ TYPESET \\
MS Code : HYDR3726 & $\checkmark$ CP & $\checkmark$ DISK \\
\hline
\end{tabular}


Invertebrate abundance and number of taxa were low at transitional and perennial sites following the spates (Fig. $4 \mathrm{a}$ and b). However, the lowest mean abundance recorded at a perennial site (57.5 ind. $0.1 \mathrm{~m}^{-2} 34$ days after flow resumed) still exceeded the highest abundance recorded at any intermittent or ephemeral site (32 ind. $0.1 \mathrm{~m}^{-2}$ at an intermittent site, 34 days after flow resumed) (Figs. $3 a$ and $4 a$ ). At transitional and perennial sites, community recovery in terms of both abundance and diversity was apparent 23 days after flow started to decline, and both measures continued to rise throughout the remainder of the study period (Fig. 4a and b); Shannon-Wiener diversity recovered more rapidly (Fig. 4c). The highest abundance $(>2,000$ individuals $0.1 \mathrm{~m}^{-2)}$ was recorded at a transitional site on the final sampling occasion (Fig. 1, site E; 102 days after flow resumption).

The persistence of aquatic fauna subsequent to dewatering of ephemeral and intermittent sites

A total of 3,086 individuals belonging to 41 taxa (25 families) were recorded from 38 sediment samples (combined weight $=38.7 \mathrm{~kg}$ ) collected from the dewatered riverbed. The Oligochaeta, including the families Tubificidae (Limnodrilus hoffmeisteri and Tubifex tubifex), Lumbricidae, Naididae and Enchytraeidae, were the most abundant taxa, accounting for $60.9 \%$ of all the recorded individuals. A cyclopoid copepod, Diacyclops bicuspidatus, and Pisidium personatum were also abundant, accounting for $15.1 \%$ and $13.0 \%$ of recorded individuals respectively. The Chironomidae, particularly the tribe Orthocladiini, were also relatively common, comprising $7.3 \%$ of all the individuals, whilst other taxa occurred at densities of only 1-2 individuals per $\sim 1 \mathrm{~kg}$ sample. Some taxa, in particular G. pulex, were only recorded on the first sampling date following the loss of surface water, and were observed in areas retaining some moisture, i.e. under rocks and in dense mats of bryophytes. Other taxa, including adult Agabus guttatus (Coleoptera: Dytiscidae) and Helophorus brevipalpis, and larval chironomids of the genus Metriocnemus, were recorded alive in dewatered sediments 29 days after surface water was lost, whilst D. bicuspidatus (both immature and adult life stages) and Smittia sp. (Chironomidae) were recorded in sediments extracted after 55 days.
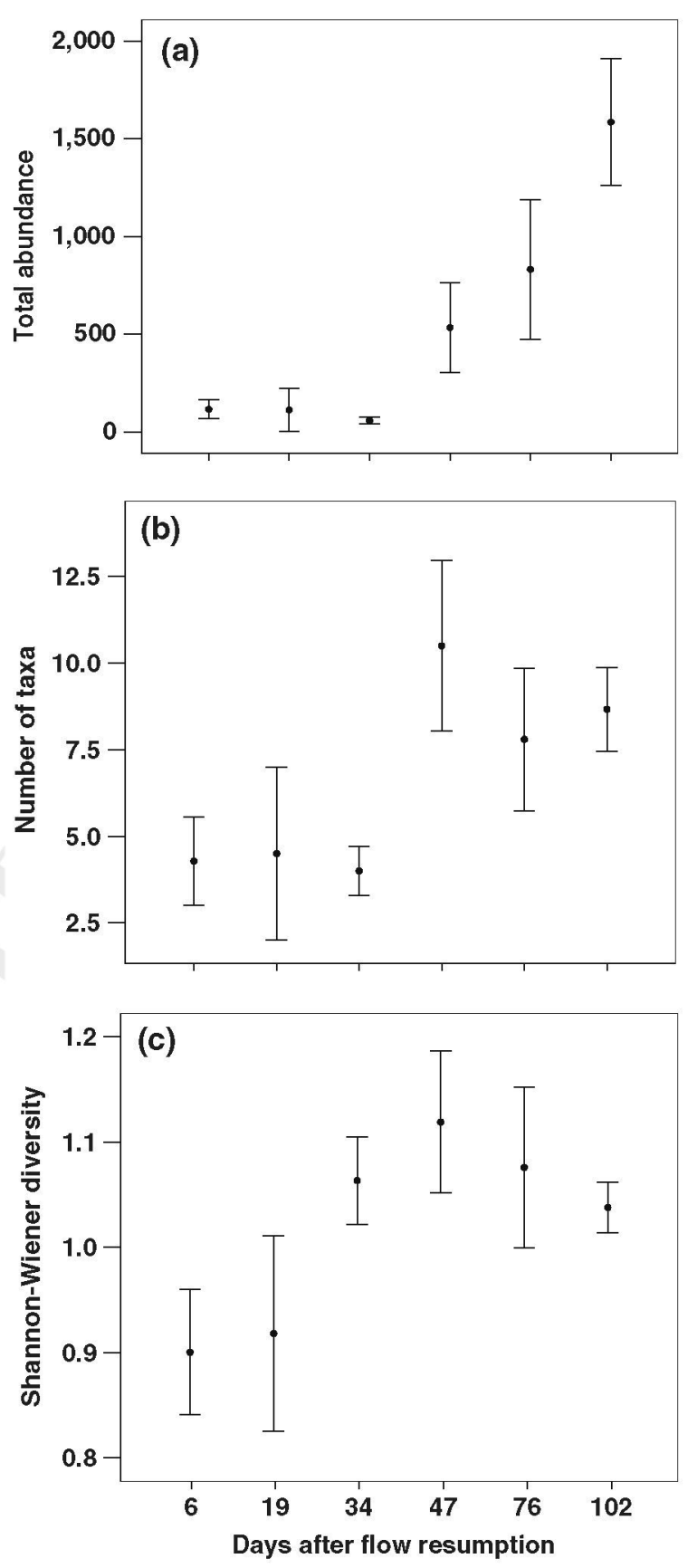

Fig. 4 Community composition (mean $\pm 1 \mathrm{SE}$ ) recorded at perennial and transitional sites during and after spates on the River Lathkill. Shown are $\mathbf{a}$ total abundance, $\mathbf{b}$ number of taxa and $\mathbf{c}$ Shannon-Wiener diversity. Number of samples: day 6: $n=6$; day $19: n=2$; day $34: n=3$; day $47: n=5$; day 76 : $n=4$; day $102: n=3$

Several insect taxa were recorded exclusively in sediments that were experimentally rehydrated, including Stenophylax sp. (Trichoptera: Limnephilidae),

\begin{tabular}{|l|lll|} 
Journal : Medium 10750 & Dispatch : 16-5-2009 & Pages : 14 \\
Article No. : 9823 & $\square$ LE & $\square$ TYPESET \\
MS Code : HYDR3726 & $\checkmark \mathrm{CP}$ & $\checkmark$ DISK \\
\hline
\end{tabular}


Nemoura cambrica (Plecoptera: Nemouridae), and Ceratopogonidae (Diptera) (Appendix 1-Electronic supplementary material). In addition, D. bicuspidatus was $>100$ times more abundant in rehydrated sediments, with all the life stages being recorded (nauplii, copepodites and adults including ovigerous females). Similarly, the Chironomidae were more abundant and diverse in rehydrated sediments (185 larvae from 13 taxa) compared with dewatered sediments (41 individuals from two taxa) (Appendix 1-Electronic supplementary material). Rehydration of sediments collected on 9th and 20th August resulted in the emergence of adult chironomids after approximately 21 days. These adults comprised Bryophaenocladius aestivus, and species of the genera Metriocnemus and Chironomus and the tribe Tanytarsini.

\section{Discussion}

Spatial and temporal variability in community composition

The importance of flow permanence in determining community structure has previously been reported for temporary streams in Mediterranean (Bonada et al., 2006), arid (Chakona et al., 2008) and temperate regions (Meyer et al., 2003), and in the present study, the flow permanence gradient in the River Lathkill headwaters was clearly reflected by invertebrate community composition despite the occurrence of an aseasonal, high magnitude flood event. Sites with lower flow permanence were characterised by reduced species richness and community abundance compared to sites with greater flow permanence, a pattern that has been reported for many other systems, including both karst and chalk streams in temperate regions (e.g. Wright et al., 1984; Meyer \& Meyer, 2000). The relatively impoverished communities of temporary streams reflect the inability of many taxa to maintain populations at sites subject to regular drying (Lytle, 2000; Suren \& Jowett, 2006). The fauna of temporary karst streams appears particularly depauperate, for example Meyer \& Meyer (2000) recorded a mean taxon richness of $<5$ taxa per site at intermittent sites in a temperate-region karst river in Germany. Similarly, in this study, mean taxon richness was $<4$ taxa at intermittent and ephemeral sites whilst surface flow persisted. Several factors are likely to contribute to the relatively species-poor nature of temporary karst stream communities, including sediment characteristics, the limited macrophyte community, and the frequent occurrence of extreme hydrological conditions. Most research studies considering other types of temporary stream communities in temperate regions have focussed on chalk streams (Ladle \& Bass, 1981; Wright et al., 1984). In contrast to limestone streams, temporary chalk streams are characterised by relatively diverse invertebrate communities, for example 75-89 taxa were recorded at intermittent sites on a small 'winterbourne' chalk stream in southern England (Wright et al., 1984; Berrie, 1992). However, despite the marked differences in chalk and karst stream communities, an inverse relationship between flow permanence and both invertebrate abundance and species richness is common to both environments (Berrie \& Wright, 1984; Meyer et al., 2003).

Streambed drying has been shown to have a greater influence on community composition than flood events (Boulton et al., 1992), and in this study, flow permanence also determined community responses to the flood event. At perennial and transitional sites, it is highly likely that the low values of community metrics recorded on the first sampling date resulted from the scouring action of the spate; considering the communities known to inhabit these reaches (Wood et al., 2005), that communities recorded at perennial sites at the start of the investigation were typical of flood-impacted sites (e.g. Suren \& Jowett, 2006), and that community recovery was subsequently recorded. In contrast, the return of flowing water to the ephemeral and intermittent reaches during the flood allowed recolonisation of the surface channel and therefore resulted in small increases in both invertebrate abundance and diversity. The combination of the detrimental impact of the spate at perennial and transitional sites, and the appearance of recolonists at temporary sites was, however, insufficient to affect the positive relationship recorded between flow permanence and both community abundance and diversity.

Four taxa were recorded at intermittent and ephemeral sites five days after flow resumed: G. pulex, A. aquaticus, Oligochaeta and Pisidium personatum, all of which are common temporary water inhabitants (Byrne \& McMahon, 1994; Montalto \& Marchese, 2005). The dominance of $G$. pulex at sites with contrasting flow permanence has been attributed to

\begin{tabular}{|l|lll|}
\hline \multirow{2}{*}{ Journal : Medium 10750 } & Dispatch : & 16-5-2009 & Pages : 14 \\
& Article No. : $\mathbf{9 8 2 3}$ & $\square$ LE & $\square$ TYPESET \\
& MS Code : HYDR3726 & $\checkmark$ CP & $\checkmark$ DISK \\
\hline
\end{tabular}


its ability to recolonise from longitudinally connected perennial surface waters and/or adjacent hypogean habitats (Lindegaard et al., 1998). In the River Lathkill, the contiguous cave and conduit system may have acted as a passive refugium from which $G$. pulex was transported into the surface channel by the spate flows (Gunn et al., 2000). Other taxa, namely the Oligochaeta and $P$. personatum, are likely to have persisted during the spate and the preceding dry phase in the surficial sediments overlying the epikarstic bedrock (Pipan, 2005), due to their morphology permitting the inhabitation of fine sediments and due to their being physiologically adapted to tolerate desiccation. Juvenile sphaeriids, for example have physiological adaptations that minimise water loss, and can persist in dewatered sediments in a dormant state (Way et al., 1980; Byrne \& McMahon, 1994). Similarly, some Oligochaeta secrete a protective cyst that facilitates desiccation resistance in dormant individuals (Montalto \& Marchese, 2005).

Consistent with previous research, the invertebrate communities of ephemeral and intermittent sites were dominated by ubiquitous and facultative taxa (i.e. those not being restricted to temporary waters) whilst surface water persisted (Fritz \& Dodds, 2004). Wright et al. (1984), for example, observed only four temporary water specialists out of a total of 233 taxa recorded from an ephemeral chalk stream in southern England. Similarly, in this study, only three taxa (Helophorus sp. larvae, Zonitoides sp. and L. truncatula) were primarily associated with the intermittent and ephemeral sites whilst surface flow persisted. These taxa are common temporary water inhabitants (Rundle et al., 2002) with physiological adaptations that confer resistance to streambed drying, for example desiccation tolerance (Landin, 1980; Costil et al., 2001) and reproduction by self-fertilisation (L. truncatula; Trouve et al., 2003). Other studies have recorded communities including a greater range of temporary water specialists, such as species of Trichoptera, Coleoptera, Ephemeroptera and the Diptera families: Ceratopogonidae and Chironomidae (Williams, 2006). In particular, four Trichoptera species (Limnephilus centralis, Micropterna lateralis, M. sequax and S. permistus (Limnephilidae)) have been associated with intermittent springs on the River Lathkill (Wood et al., 2005). In this study, the absence of such common temporary water inhabitants during the period of surface flow largely reflects the life histories of aquatic insects, since summer sampling would have coincided with the terrestrial adult stage of many species. Additional factors in this current study may have included the removal of temporary water specialists by the scouring spate flows, the disruption of lifecycles by the unpredictable timing of the spate (Lytle \& Poff, 2004).

The persistence of aquatic invertebrates subsequent to streambed drying

Previous studies considering the refugial capacity of the hyporheic zone have suggested an existence of coarse-grained substratum (and hence, large interstices; Gagneur \& Chaoui-Boudghane, 1991) and the retention of free water (Boulton \& Stanley, 1995) as necessary features of an effective refugium. However, the River Lathkill headwaters do not have typical hyporheic sediments, the substratum instead comprising exposed epikarstic bedrock overlain in places by fine-grained sediments. The rapid recolonisation of the surface channel following flow reactivation had indicated that these sediments provided a refugium for a few taxa (e.g. Oligochaeta and $P$. personatum), despite lacking both large interstices and free water. Indeed, the subsequent to investigation of dewatered sediments subsequent to streambed drying demonstrated that taxa including A. guttatus, H. brevipalpis (Coleoptera: Helophoridae), Diacyclops bicuspidatus and several Chironomidae (e.g. Smittia sp. and Metriocnemus sp.) were inhabiting the surficial sediments $>1$ month after surface flow ceased. However, these sediments were not used as a refugium by all the taxa; $G$. pulex: for example, was observed alive under larger substratum clasts on the first sampling occasion after surface water was lost, but not during subsequent to surveys. The inability of G. pulex to exploit this potential refugium likely reflects the fine-grained nature of the sediments, since Gammarus species have been observed to migrate into the hyporheic zone to depths of $2 \mathrm{~m}$ during spate conditions where interstitial spaces allow (Dole-Olivier \& Marmonier, 1992).

The communities recorded in rehydrated sediments comprised more taxa at greater abundances compared with those of dewatered sediments preserved immediately after collection, indicating that physiological and life history survival strategies had been used in

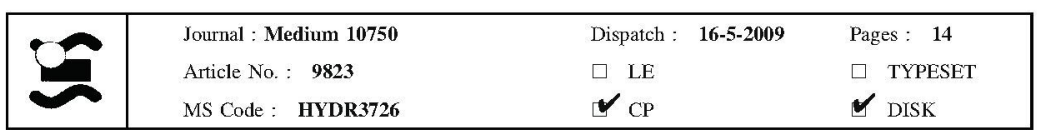


conjunction with behavioural refugium inhabitation. Cyclopoid copepods of the family Cyclopidae, for example, are known to survive unfavourable environmental conditions as dormant juveniles (Dahms, 1995), and in this study, the abundance of all the life stages of Diacyclops bicuspidatus in rehydrated samples indicated the use of this strategy during streambed drying. Similarly, the Chironomidae were more abundant and diverse in rehydrated sediments (13 genera) compared with dewatered sediments (two genera), suggesting that many taxa had persisted as dormant eggs (Vinogradova, 2007). Experimental rehydration therefore allowed chironomid development to resume, with adult emergence occurring after $\sim 3$ weeks, indicating the importance of rapid development in aquatic larvae as a survival strategy of temporary water inhabitants (McLachlan, 1983).

Several taxa not recorded at intermittent or ephemeral sites whilst surface flow persisted were subsequently observed in sediment samples, including Nemoura cambrica nymphs, Stenophylax sp. larvae, and adult Anacaena globulus (Coleoptera: Hydrophilidae) and $A$. guttatus. These insect taxa may have been present whilst surface flows persisted but not sampled due to low abundance; however, they are also known to have life history adaptations that facilitate survival during streambed drying. Stenophylax permistus, for example is particularly common in temporary reaches of the River Lathkill (Wood et al., 2005), emerging from the river prior to streambed drying and aestivating in the terrestrial environment as adults until surface water returns (Williams, 1996). Stoneflies of the family Nemouridae are also common temporary water inhabitants (Williams, 2006) and certain species are associated with intermittent sections of the River Lathkill, where they reach peak abundance during early spring, prior to the loss of surface water (Wood et al., 2005). In addition, several Dytiscidae beetles, including the genus Agabus, have been recorded in temporary waters throughout the local area (Wood et al., 2005), and also occur in temporary water habitats in other regions (e.g. Fenoglio et al., 2006). The presence of these temporary water specialists in the dry sediment samples indicates that their earlier absence subsequent to the resumption of surface flow was probably due to the life history and physiological survival strategies of individual species, and did not reflect any long-term detrimental impacts of the aseasonal spate.

\section{Conclusions}

Climate change forecasts for the region studied (i.e. the East Midlands of England) indicate that in the coming decades, summers may be characterised by higher temperatures and reduced rainfall (Shackley et al., 2001). These changes are likely to increase both the spatial and temporal extent of streambed drying events, particularly in hydrologically responsive rivers such as those in karst landscapes. Our research has demonstrated the persistence of invertebrate taxa in the fine sediments overlying the bedrock of one such karst river, and this habitat can therefore act as a functional equivalent of the hyporheic zone refugium during streambed drying, despite lacking attributes considered central to the refugial capacity of the latter (Gagneur \& Chaoui-Boudghane, 1991; Olsen and Townsend, 2005). However, the species able to exploit these fine-grained sediments as a refugium appear limited, and although the persistence of some species was enhanced by desiccation tolerance, the small interstitial spaces and lack of free water prevented the survival of others. This research has thus highlighted the importance of physiological as well as behavioural adaptations in promoting invertebrate resistance and resilience during streambed drying, with many species using a combination of strategies to facilitate survival. Future research should examine the abiotic and biotic factors that control the use of subsurface sediments as refugia by aquatic invertebrates during both spate and drying events, as well as the relative importance of behavioural (i.e. refugium use, both active and passive), physiological (e.g. desiccation tolerance) and life-history (e.g. timing of terrestrial life stages) adaptations in promoting invertebrate persistence during extreme hydrological events. Such research will contribute to the understanding of potential invertebrate community responses to future environmental change.

Acknowledgements AMG acknowledges the support of the Nuffield Foundation Undergraduate Research Science Bursary (URB $\backslash 34138$ ) entitled: 'The survival of macroinvertebrate fauna within ephemeral streams', under the supervision of PJW to undertake part of this research. We would like to thank Natural England for access to their site and particularly Philip Bowler for support and encouragement throughout the research. Hydrological data (precipitation and river discharge) were kindly provided the Environment Agency of England and Wales, and by the Limestone Research Group at the University of Birmingham. We thank the associated editor, and two

\begin{tabular}{|l|lll|}
\hline & Journal : Medium 10750 & Dispatch : 16-5-2009 & Pages : 14 \\
Article No. : 9823 & $\square$ LE & $\square$ TYPESET \\
MS Code : HYDR3726 & $\checkmark$ CP & $\checkmark$ DISK \\
\hline
\end{tabular}


anonymous reviewers for their constructive comments on an earlier version of this manuscript.

\section{References}

Berrie, A. D., 1992. The chalk-stream environment. Hydrobiologia 248: 3-9.

Bonada, N., M. Rieradevell, N. Prat \& V. H. Resh, 2006. Benthic macroinvertebrate assemblages and macrohabitat connectivity in Mediterranean-climate streams of northern California. Journal of the North American Benthological Society $25: 32-43$.

Boulton, A. J., 1989. Over-summer refuges of aquatic macroinvertebrates in two intermittent streams in central Victoria. Transactions of the Royal Society of Southern Australia 113: 22-34.

Boulton, A. J., 2003. Parallels and contrasts in the effects of drought on stream macroinvertebrate assemblages. Freshwater Biology 48: 1173-1185.

Boulton, A. J. \& E. H. Stanley, 1995. Hyporheic processes during flooding and drying in a Sonoran Desert stream. II. Faunal dynamics. Archiv für Hydrobiologie 134: 27-52.

Boulton, A. J., C. G. Peterson, N. B. Grimm \& S. G. Fisher, 1992. Stability of an aquatic macroinvertebrate community in a multiyear hydrologic disturbance regime. Ecology 73: 2192-2207.

Byrne, R. A. \& R. F. McMahon, 1994. Behavioural and physiological responses to emersion in freshwater bivalves. American Zoologist 34: 194-204.

Chakona, A., C. Phiri, C. H. D. Magadza \& L. Brendonck, 2008. The influence of habitat structure and flow permanence on macroinvertebrate assemblages in temporary rivers in northwestern Zimbabwe. Hydrobiologia 607: 199-209.

Clinton, S. M., N. B. Grimm \& S. G. Fisher, 1996. Response of a hyporheic invertebrate assemblage to drying disturbance in a desert stream. Journal of the North American Benthological Society 15: 700-712.

Costil, K., G. B. J. Dussart \& J. Daguzan, 2001. Biodiversity of aquatic gastropods in the Mont St-Michel basin (France) in relation to salinity and drying of habitats. Biodiversity and Conservation 10: 1-18.

Dahms, H., 1995. Dormancy in the Copepoda-an overview. Hydrobiologia 306: 199-211.

Datry, T., S. T. Larned \& M. R. Scarsbrook, 2007. Responses of hyporheic invertebrate assemblages to large scale variation in flow permanence and surface-subsurface exchange. Freshwater Biology 52: 1452-1462.

Dole-Olivier, M.-J. \& P. Marmonier, 1992. Effects of spates on the vertical distribution of the interstitial community. Hydrobiologia 230: 49-61.

Erman, N. A. \& D. C. Erman, 1995. Spring permanence, Trichoptera species richness, and the role of drought. Journal of the Kansas Entomological Society 68: 50-64.

Fenoglio, S., T. Bo \& G. Bosi, 2006. Deep interstitial habitat as a refuge for Agabus paludosus (Fabricus) (Coleopter: Dytiscidae) during summer droughts. The Coleoptersists Bulletin 60: 37-41.
Fritz, K. M. \& W. K. Dodds, 2004. Resistance and resilience of macroinvertebrate assemblages to drying and flood in a tallgrass prairie stream system. Hydrobiologia 527: 99-112.

Furse, M. T., J. F. Wright, P. D. Armitage \& D. Moss, 1981. An appraisal of pond-net samples for biological monitoring of lotic macroinvertebrates. Water Research 15: 679-689.

Gagneur, J. \& C. Chaoui-Boudghane, 1991. Sur le rôle du milieu hyporhéique pendant l'assèchement des oueds de l'Ouest Algérien. Stygologia 6: 77-89.

Gunn, J., P. Hardwick \& P. J. Wood, 2000. The invertebrate community of the Peak-Speedwell cave system, Derbyshire, England-pressures and considerations for conservation management. Aquatic Conservation: Marine and Freshwater Ecosystems 10: 353-369.

Hughes, D. A., 2005. Hydrological issues associated with the determination of environmental water requirements of ephemeral rivers. River Research and Applications 21: 899-908.

Humphries, P. \& D. S. Baldwin, 2003. Drought and aquatic ecosystems: an introduction. Freshwater Biology 48: 1141-1146.

Kramer, C. Y., 1956. Extension of multiple range tests to group means with unequal numbers of replicators. Biometrics 12: 309-310.

Lake, P. S., 2000. Disturbance, patchiness and diversity in streams. Journal of the North American Benthological Society 19: 573-592.

Lancaster, J. \& A. G. Hildrew, 1993. Flow refugia and the microdistribution of lotic macroinvertebrates. Journal of the North American Benthological Society 12: 385-393.

Ladle, M. \& J. A. B. Bass, 1981. The ecology of a small chalk stream and its responses to drying during drought conditions. Archiv für Hydrobiologie 90: 448-466.

Landin, J., 1980. Habitats, life histories, migration and dispersal by flight of two water-beetles Helophorus brevipalpis and $H$. strigifrons (Hydrophilidae). Holartic Ecology 3: 190-201.

Lindegaard, C., K. P. Brodersen, P. Wiberg-Larsen \& J. Skriver, 1998. Multivariate analyses of macrofaunal communities in Danish springs and springbrooks. In Botosaneanu, L. (ed.), Studies in Crenobiology: The Biology of Springs and Springbrooks. Backhuys Publishers, Leiden: 201-210.

Lytle, D. A., 2000. Biotic and abiotic effects of flash flooding in a montane desert stream. Archiv für Hydrobiologie 150: $85-100$

Lytle, D. A. \& N. L. Poff, 2004. Adaptation to natural flow regimes. Trends in Ecology \& Evolution 19: 94-100.

Marsh, T., 2008. A hydrological overview of the summer 2007 floods in England and Wales. Weather 63: 274-279.

McLachlan, A., 1983. Life-history tactics of rain-pool dwellers. Journal of Animal Ecology 52: 545-561.

Meyer, A. \& E. I. Meyer, 2000. Discharge regime and the effect of drying on macroinvertebrate communities in a temporary karst stream in East Westphalia (Germany). Aquatic Science 62: 216-231.

Meyer, A. M., E. I. Meyer \& C. Meyer, 2003. Lotic communities of two small temporary karstic stream systems (East Westphalia, Germany) along a longitudinal gradient of hydrological intermittency. Limnologica 33: 271-279.

\begin{tabular}{|l|lll|} 
Journal : Medium 10750 & Dispatch : 16-5-2009 & Pages : 14 \\
Article No: : 9823 & $\square$ LE & $\square$ TYPESET \\
MS Code : HYDR3726 & $\checkmark \mathrm{CP}$ & $\checkmark$ DISK \\
\hline
\end{tabular}


965

966

967

968

969

970

971

972

973

974

975

976
Monk, W. A., P. J. Wood, D. M. Hannah \& D. A. Wilson, 2008. Macroinvertebrate community response to interannual and regional river flow regime dynamics. River Research and Applications 24: 988-1001.

Montalto, L. \& M. Marchese, 2005. Cyst formation in Tubificidae (Naidinae) and Opistocystidae (Annelida, Oligochaeta) as an adaptive strategy for drought tolerance in fluvial wetlands of the Paraná River, Argentina. Wetlands 25: 488-494.

Olsen, D. A. \& C. R. Townsend, 2005. Flood effects on invertebrates, sediments and particulate organic matter in the hyporheic zone of a gravel-bed stream. Freshwater Biology 50: 839-853.

Pisces Conservation Ltd., 2002. Species Diversity and Richness-3.03. Pisces Conservation Ltd., Lymington, UK

Pipan, T., 2005. Epikarst-a Promising Habitat: Copepod fauna, its Diversity and Ecology: a Case Study from Slovenia (Europe). ZRC Publishing, Zalozba.

Rundle, S. D., A. Foggo, V. Choiseul \& D. T. Bilton, 2002. Are distribution patterns linked to dispersal mechanism? An investigation using pond invertebrate assemblages. Freshwater Biology 47: 1571-1581.

Salavert, V., C. Zamora-Muñoz, M. Ruiz-Rodríguez, A. Fernández-Cortés \& J. J. Soler, 2008. Climatic conditions, diapause and migration in a troglophile caddisfly. Freshwater Biology 53: $1606-1617$.

Shackley, S., J. Kersey, R. Wilby \& P. Fleming, 2001. Changing by Degrees: The Potential Impacts of Climate Change in the East Midlands. Ashgate Publishing Ltd, UK, Farnham.

Smith, H. \& P. J. Wood, 2002. Flow permanence and macroinvertebrate community variability in limestone spring systems. Hydrobiologia 487: 45-58.

Smith, H., P. J. Wood \& J. Gunn, 2003. The influence of habitat structure and flow permanence on invertebrate communities in karst spring systems. Hydrobiologia 510 : $53-66$.

Stanley, E. H., D. L. Buschmann, A. J. Boulton, N. B. Grimm \& S. G. Fisher, 1994. Invertebrate resistance and resilience to intermittency in a desert stream. American Midland Naturalist 131: 288-300.
Suren, A. M. \& I. G. Jowett, 2006. Effects of floods versus low flows on invertebrates in a New Zealand gravel-bed river. Freshwater Biology 51: 2207-2227.

ter Braak, C. J. F. \& P. Šmilauer, 2002. CANOCO Reference manual and CanoDraw for Windows User's guide: Software for Canonical Community Ordination (version 4.5). Microcomputer Power, Ithaca, NY, USA: 500 pp.

Trouve, S., L. Degen, F. Renaud \& J. Goudet, 2003. Evolutionary implications of a high selfing rate in the freshwater snail Lymnaea truncatula. Evolution 57: 2303-2314.

Tukey, J. W., 1949. Comparing individual means in the analysis of variance. Biometrics 5: 99-114.

Vinogradova, E. B., 2007. Diapause in aquatic insects, with emphasis on mosquitoes. In Alekseev, V. R., B. T. De Stasio \& J. J. Gilbert (eds), Diapause in Aquatic Invertebrates: Theory and Human Use. Springer, Dordrecht, The Netherlands.

Way, C. M., D. J. Hornbach \& A. J. Burky, 1980. Comparative life history tactics of the Sphaeriid clam, Musculium partumeium (Say), form a permanent and a temporary pond. American Midland Naturalist 104: 319-327.

Williams, D. D., 1996. Environmental constraints in temporary fresh waters and their consequences for the insect fauna. Journal of the North American Benthological Society 15: 634-650.

Williams, D. D., 2006. The Biology of Temporary Waters. Oxford University Press, Oxford.

Wood, P. J., J. Gunn, H. Smith \& A. Abas-Kutty, 2005. Flow permanence and macroinvertebrate community diversity within groundwater dominated headwater streams and springs. Hydrobiologia 545: 55-64.

Wright, J. F., 1981. A 9-year study of the life-cycle of Ephemera danica Müll (Ephemeridae, Ephemeroptera) in the River Lambourn, England. Ecological Entomology 6: 321-331.

Wright, J. F., P. D. Hiley, D. A. Cooling, A. C. Cameron, M. E. Wigham \& A. D. Berrie, 1984. The invertebrate fauna of a small chalk stream in Berkshire, England, and the effect of intermittent flow. Archiv für Hydrobiologie 99: 176-199.
1005

1006

1007

1008

1009

1010

1011

1012

1013

1014

1015

1016

1017

1018

1019

1020

1021

1022

1023

1024

1025

1026

1027

1028

1029

1030

1031

1032

1033

1034

1035

1036

1037

1038

1039

1040

1041

1042

1043

1044

\begin{tabular}{|l|lll|}
\hline & Journal : Medium 10750 & Dispatch : 16-5-2009 & Pages : 14 \\
Article No. : 9823 & $\square \mathrm{LE}$ & $\square$ TYPESET \\
MS Code : HYDR3726 & $\checkmark \mathrm{CP}$ & $\checkmark$ DISK \\
\hline
\end{tabular}

